\title{
From the abstract to the concrete - Implementation of an innovative tool in home care
}

\section{Kajamaa, Anu}

2018-02

Kajamaa , A \& Schulz , K-P 2018 , ' From the abstract to the concrete - Implementation of an innovative tool in home care ', Health Services Management Research , vol. 31 , no. 1 , pp. 2-10 . https://doi.org/10.1177/0951484817724581

http://hdl.handle.net/10138/238414

https://doi.org/10.1177/0951484817724581

other

acceptedVersion

Downloaded from Helda, University of Helsinki institutional repository.

This is an electronic reprint of the original article.

This reprint may differ from the original in pagination and typographic detail.

Please cite the original version. 


\title{
From the abstract to the concrete - Implementation of an innovative tool in home care
}

\author{
Anu Kajamaa, University of Helsinki, Finland, Klaus-Peter Schulz, ICN Business \\ School, Nancy, France
}

\begin{abstract}
Background: The implementation of innovations in practice is a critical factor for change and development processes in health and home care. We therefore analyze how an innovative tool - a Mobility Agreement to maintain physical mobility of home care clients was implemented in Finnish home care.
\end{abstract}

Methods: Our study involves ethnographic research of 13 home care visits, two years after the Mobility Agreement was implemented. We analyze the emergence of contradictions, the motives of the actors and the use of artifacts supporting or inhibiting the implementation. Two in-depth cases illustrate the implementation of the Mobility Agreement in home care visits.

Findings: Our findings show that, first, to achieve practice change and development, the innovation implementation requires the overcoming of contradictions in the implementation process. Second, it calls for the emergence of a shared motive between the actors to transform the abstract concept of an innovation into a concrete practice. Third, artifacts, customary to the clients are important in supporting the implementation process. Fourth, the implementation brings about a modification of the innovation and the adopting social system.

Conclusions: Innovation implementation should be seen as a transformation process of an abstract concept into a concrete practice, enabled by the actors involved. Concept design and implementation should be closely linked. In health/home care innovation management, the implementation of innovations needs to be understood as a complex collective learning process. Results can be far reaching - in our case leading to change of home care workers' professional understanding and elderly clients' mobility habits.

Keywords: implementation of innovation, shared motive, contradiction, artifact, expansive learning, home care

\section{Introduction}

Considering innovation and development in health care, much empirical and conceptual research has been carried out studying the core processes of ideation, concept development and organizational design ${ }^{1,2,3}$. It is often argued that in health care settings, the implementation of new concepts or practices in a sustainable way constitutes the most critical phase ${ }^{4,5}$. Health care innovation implementation efforts often fail as unexpected obstacles and conflicts may paralyze the implementation processes ${ }^{6}$. Implementation therefore requires an increasingly strong emphasis from the design of an innovation towards change and development of operational practice on a grassroots level of daily work ${ }^{7}$. 
The implementation of innovations has been studied from different perspectives, such as adaptation $^{7}$, diffusion and adoption of innovation ${ }^{1,8}$ and in connection to sustainability ${ }^{5}$. Several studies concerning the implementation of innovations in health care emphasize the aspect of routinization ${ }^{1}$ and the importance of context factors when a new concept, practice or technology is put into operation ${ }^{5}$. Particularly in the case of inventing new practices, the implementation context of the innovation and the interaction of different actors involved play a crucial role ${ }^{9}$.

In this article, we explore home care visits where an innovative concept aiming to increase the mobility of home care clients in the city of Helsinki, Finland is introduced. This innovation called the "Mobility Agreement" (referred to in the following as MA) was invented in a participatory process using the Change Laboratory method ${ }^{10,11}$. The idea of the Change Laboratory is based on activity theory, viewing contradictions as drivers for change and innovation. In the research-assisted Change Laboratory sessions in home care, contradictions were identified in a discursive process aiming at changes of participants' mindsets and the development of new innovative tools and practices. The implementation of the MA after a Change Laboratory is a critical process as in its concrete application in a particular context new contradictions may appear ${ }^{6,11}$. These contradictions are often caused by the resistance of the actors in the adopting system ${ }^{12}$.

How an innovative, abstract concept can be implemented to change and develop organizational practice is still poorly understood. To partially bridge this research gap, we study the implementation of the MA in 13 home care visits to elderly clients' homes. The MA can be seen as an innovation, as it promotes mobility practices which are radically new to the traditional script of home care visits and potentially brings about change and develops home care and the clients' well-being. Taking an activity-theoretic view, we analyze three issues in the implementation, namely the emergence of contradictions, the development of a shared motive for change among the actors and the use of artifacts.

\section{On the implementation of innovations}

The following theoretic concepts are frequently referred to in previous literature on innovation implementation. Diffusion is defined as spreading a new product or idea in a social system $^{12}$, which results in its acceptance and subsequently its use. Diffusion is often seen as the result of the communication of the new idea and its adoption of a social system ${ }^{12,13}$. Adoption studies usually focus on the implementation in a social system to identify enablers and inhibitors of the adoption process ${ }^{14}$. Adaptation of the novel practices is much less explored ${ }^{7,15}$. Adaptation can be depicted as "the process by which an adopter tries to create a better 'fit' between a practice and the adopters' particular needs, where the fit means 'the degree to which the characteristics of a practice are consistent with the (per-

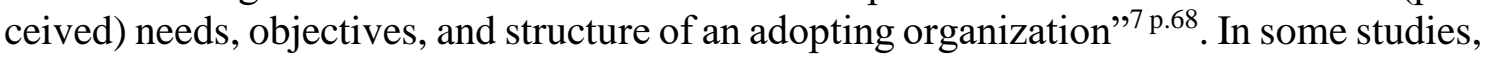
communication, adoption, adaptation and diffusion of process and social innovations is seen as intertwined ${ }^{17}$. Furthermore, the successful implementation of novelty over a period of time is seen as innovation sustainability.

Implementation can be seen as a re-invention of the theoretic concept towards a concrete practical solution. In this process, the adopters actively change the meaning of the prac- 
tice $^{12}$. Hence, implementation goes along with transformation. The consequences of implementation processes, however, cannot always be predicted and the efforts may lead to undesired adaptations and unanticipated outcomes ${ }^{9,12,15}$. Practice-based studies importantly stress that adopters play a decisive role in the generation, coercive adoption, and bottom-up adaptation of process- and social innovations ${ }^{16}$. Yet, innovation management frequently takes place as a top-down process and the role of actors of the adopting system is often that of a passive legitimizer ${ }^{16}$. For a sustainable implementation, the legitimization and active participation of the diverse actor groups is, however, essential ${ }^{5}$.

We see innovation implementation as a contradiction-laden, learning process of the participating actors belonging to a social system. In this process, the actors communicate, design, open up, negotiate, re-conceptualize, adopt, adapt and appropriate an innovation in their local context. In activity-theoretic terms, innovation design and implementation may generate expansive learning actions ${ }^{11,17}$. In our home care example, the concept development is driven by health and home care professionals on a management level including funding and decision making institutions as well as the clients' representatives. The implementation is carried out by home care workers and their clients,

\section{The role of contradictions, motives and artifacts in the implementation process}

The Change Laboratory method provides a platform for collective reflection of work activity $^{18}$. In a Change Laboratory intervention an interdisciplinary group of participants tries to improve its practices with a team of researchers by collectively analyzing its past, present and future practice. The analysis often brings about contradictions within the work activity of the participants or between their different (disciplinary) views ${ }^{19}$. Usually, the contradictions cannot be solved through a mere adaptation of practice to an innovation. Contradictions trigger the questioning of the current understandings, identities or routines of the work and their resolving requires a deep rethinking of the practice ${ }^{18}$. In the implementation process of the innovation further contradictions may appear ${ }^{11,21}$ between the actors and the new concept and its intended use in practice. The motives of the concept designers, the promotors and the actors in the adopting system are likely to differ. Such diversity often creates challenges to the implementation of the abstract concept into the concrete practice.

Further, collective creation of shared motives and innovative new concepts and practices of work is needed. Taking an activity theoretical stance, the shared motive is seen as always object-related ${ }^{20}$, in our case the overall object being the enhancement of the fragile home care clients' physical mobility and well-being. Artifacts (tools and instruments) can mediate actions between actors and objects and are crucial in promoting expansive learning $^{22}$. The mediating artefacts in the design phase of a Change Laboratory typically involve communication and reflection tools, such as video- and audio recordings of the work activity, minutes, drawings or statistical data brought to the intervention sessions by the researchers ${ }^{11}$.

Change Laboratory intervention projects have especially enhanced new innovative forms of collaboration and multiprofessional practice in health care, for instance organizational development of surgery units in hospitals, in clinics of municipal health centers and in health center consortiums ${ }^{11,23}$. In the following case example of elderly home care, the 
change and development of the home care activity can be seen as a two phase process, including seven specific learning actions of expansive learning (see fig. 1). The first phase is what we call the design generating a mainly abstract concept and, at this stage, decontextualized "cell" of an innovation. This phase involves the participants' questioning of the current practice, its analysis and modelling and examination with new solutions. The second phase involves the implementation of the innovative concept in a concrete practice in a local organizational context including reflection and consolidation of the new practice (see fig. 1).

Usually, the researcher leaves the organization after the testing of the innovation created in the conducted Change Laboratory sessions. The implementation phase is then on the responsibility of the actors of the organization and little is known about the consequences of the implementation ${ }^{9}$. The implementation process of the MA, designed in a Change Laboratory project, is described in the following.

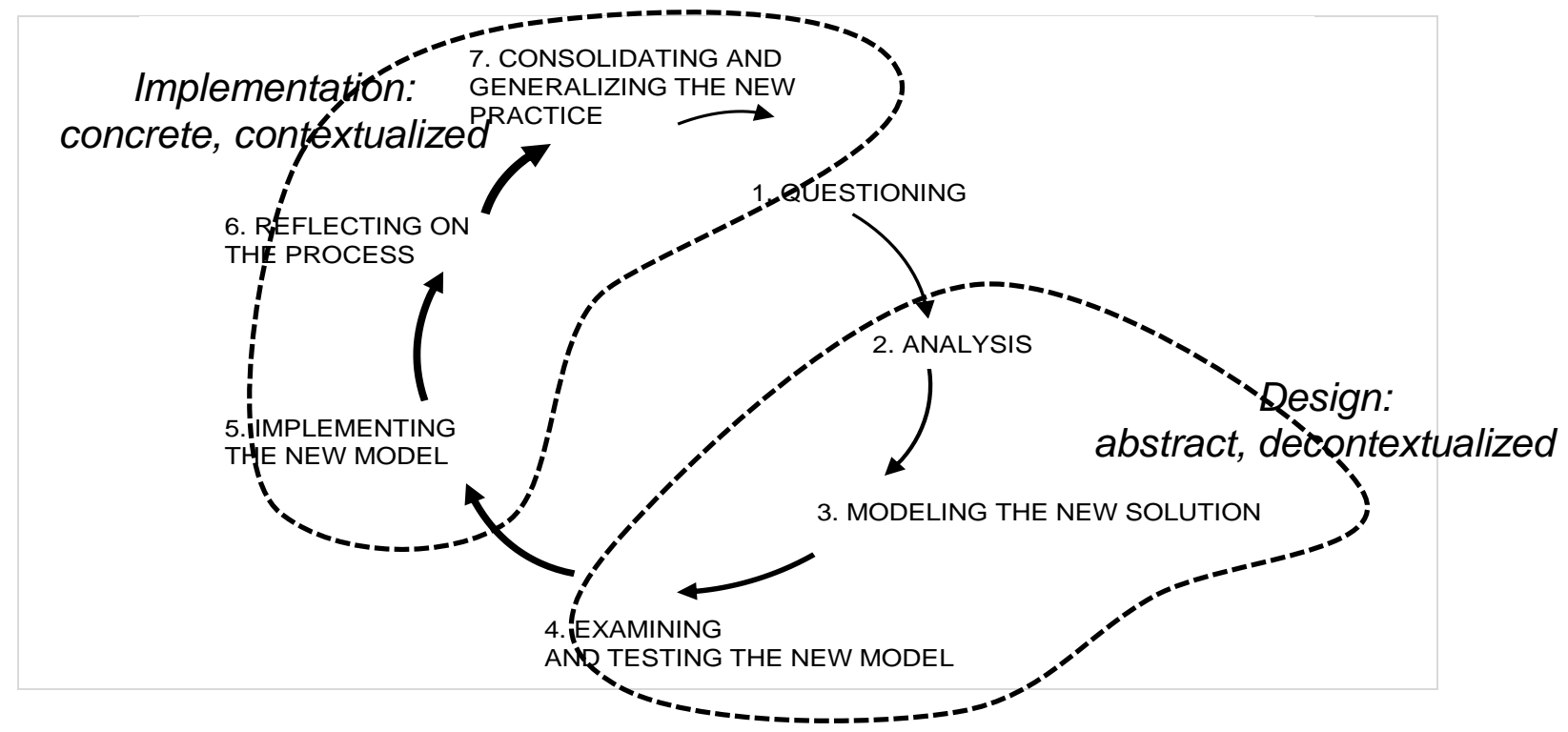

Fig 1: The design and implementation of an innovation as an expansive learning process enabling a transformation from an abstract concept toward a new concrete practice (modified from ${ }^{22}$ )

\section{Implementing a Mobility Agreement in home care}

In Finland, as in many other industrialized countries, the poor mobility of elderly people living at home increases their social exclusion and costly hospitalization. The advancement of activity and mobility are therefore central challenges for the clients to improve their quality of life and to enable a safe living at home. The need for increasing regular physical activity of the elderly is a generally known fact for the city of Helsinki home care workers and their clients. In Helsinki home care, home care workers (usually a nurse) visit the clients a few times a week in the client's home. The promotion of mobility in the home is, however, not typically in the focus of home care visits. The services provided to the clients during home care visits are primarily routine supply tasks such as medicine dispensation, food supply, personal hygiene and health-care ${ }^{10}$. 
The MA is a document and a tool designed for negotiating and deciding on the execution of different kinds of daily mobility exercises between the home care workers and their clients. It also aims at preventing social exclusion of the elderly, developing home care visits and enhancing the collaboration between the clients and the home care workers. As a consequence of the use of MA, the workers are supposed to reduce the managing of home care duties on behalf of old person as well as guide and encourage clients to exercise regularly. The tool was created by various organizations and professional groups in a Change Laboratory process and was thereafter implemented in the city of Helsinki home care. A year later the tool won the city of Helsinki Mayor's achievement prize. The challenge, justifying the importance of our study, is to implement the MA in the whole city of Helsinki home care. Our data was collected two years after the MA tool was first implemented. In the following, we will present the methods of data collection and data analysis of this study.

\section{Methodology of the study}

We carried out an ethnographic field research ${ }^{24}$ and a multi-level analysis of the implementation of the MA in home care. We observed 13 home care workers' visits to the clients' homes where the MA was meant to be used. The observed visits were randomly selected for our study by the home care managers. Each client and employee was interviewed by the researcher after the visit. Notes were made during the observations and the interviews. The visits lasted 45-90 minutes, the interviews about 30 minutes. In this study, we focus on the observational data. The interviews are secondary data supporting our interpretations.

All of the visits were videotaped and the videos were transcribed into texts for analysis. First, the observation and interview notes, as well as the transcribed videos were analyzed first, mainly, by using thematic analysis ${ }^{25}$. Then, the analysis was theory driven, based on our activity theoretic understanding of expansive learning and development. Applying this theory, the "intermediate concepts" of contradictions, mediating artefacts and motives of the actors were identified and analyzed in the implementation of the MA. A summary of the data analysis of all of 13 cases is presented in the following table 1 . The shift from an abstract MA concept to concrete practice in the implementation process is illustrated by presenting two case examples from home care visits.

\section{Findings: summary of the Mobility Agreement implementation}

Table 1 presents an overview of the analysis of the contradictions and motives within and bet-ween the actors involved in the implementation of the MA as well as their artifact use depicted in our data. 


\begin{tabular}{|c|c|c|c|}
\hline Client and age & Contradictions & Motives & Artifacts used \\
\hline 1) Woman, 92 years & $\begin{array}{l}\text { The client's will to get } \\
\text { better and to go to summer } \\
\text { cottage vs. the worker } \\
\text { concentrating on measur- } \\
\text { ing blood pressure }\end{array}$ & $\begin{array}{l}\text { Taking the walker into use } \\
\text { and going out, perhaps to the } \\
\text { summer cottage }\end{array}$ & $\begin{array}{l}\text { Exercise bike, walker, exer- } \\
\text { cise instructions, blood pres- } \\
\text { sure meter, scale }\end{array}$ \\
\hline 2) Woman, 86 years & $\begin{array}{l}\text { The client's will to get } \\
\text { better and to go out vs. the } \\
\text { client's pessimism to- } \\
\text { wards her own abilities }\end{array}$ & $\begin{array}{l}\text { Start going out with a sum- } \\
\text { mer worker, going to the } \\
\text { gym }\end{array}$ & $\begin{array}{l}\text { Walker (not used), dumb- } \\
\text { bells, instructions for foot } \\
\text { and back exercises }\end{array}$ \\
\hline $\begin{array}{l}\text { 3) Woman, } 87 \text { years } \\
\text { (presented later as } \\
\text { case 1) }\end{array}$ & $\begin{array}{l}\text { The client follows exer- } \\
\text { cise instructions during } \\
\text { the visit vs. the client does } \\
\text { not at all exercise alone }\end{array}$ & $\begin{array}{l}\text { Doing exercises with move- } \\
\text { ment supporting device to- } \\
\text { gether with the employee }\end{array}$ & $\begin{array}{l}\text { Movement supporting de- } \\
\text { vice, capability test, kitchen } \\
\text { chair, exercise instructions }\end{array}$ \\
\hline 4) Woman, 95 years & $\begin{array}{l}\text { Client's low motivation to } \\
\text { exercise vs. worker leaves } \\
\text { the responsibility to other } \\
\text { workers }\end{array}$ & $\begin{array}{l}\text { Doing exercises with the } \\
\text { movement supporting device } \\
\text { together with other employ- } \\
\text { ees }\end{array}$ & $\begin{array}{l}\text { Stoll, movement supporting } \\
\text { device to lift the client to } \\
\text { and from her bed }\end{array}$ \\
\hline 5) Man, 79 years & $\begin{array}{l}\text { The client's confusion to- } \\
\text { wards the exercise instruc- } \\
\text { tions vs. the worker imple- } \\
\text { menting MA }\end{array}$ & $\begin{array}{l}\text { Transcending the client's } \\
\text { confusion and incorporating } \\
\text { exercises to the client's daily } \\
\text { life }\end{array}$ & $\begin{array}{l}\text { The client's bed as an exer- } \\
\text { cise "platform", exercise in- } \\
\text { structions }\end{array}$ \\
\hline 6) Woman, 80 years & $\begin{array}{l}\text { Client's low motivation to } \\
\text { exercise vs. her will to get } \\
\text { better and go grocery } \\
\text { shopping }\end{array}$ & $\begin{array}{l}\text { Incorporating exercises to } \\
\text { the client's daily life and go- } \\
\text { ing to an exercise group }\end{array}$ & Dumbbells, kitchen chairs \\
\hline 7) Woman, 86 years & $\begin{array}{l}\text { Client's fear towards fall- } \\
\text { ing vs. the worker imple- } \\
\text { menting MA }\end{array}$ & $\begin{array}{l}\text { Incorporating exercises to } \\
\text { the client's daily life }\end{array}$ & Dumbbells, chair, knitting \\
\hline 8) Woman, 78 years & $\begin{array}{l}\text { Client's weak condition } \\
\text { vs. the worker implement- } \\
\text { ing MA }\end{array}$ & $\begin{array}{l}\text { Incorporating exercises to } \\
\text { the client's daily life, at least } \\
\text { small moments of exercise }\end{array}$ & $\begin{array}{l}\text { Dumbbells, chair and exer- } \\
\text { cise instructions }\end{array}$ \\
\hline 9) Woman, 84 years & $\begin{array}{l}\text { Client's will to go out vs. } \\
\text { worker has no resources to } \\
\text { take her out }\end{array}$ & $\begin{array}{l}\text { Start going out with the } \\
\text { worker at least once a week }\end{array}$ & - \\
\hline 10) Woman, 89 years & $\begin{array}{l}\text { The client went through } \\
\text { an operation and is in poor } \\
\text { condition vs. worker con- } \\
\text { centrates on regular home } \\
\text { care visit tasks rather than } \\
\text { mobility }\end{array}$ & $\begin{array}{l}\text { Incorporating exercises to } \\
\text { the client's daily life (but no } \\
\text { shared responsibility) }\end{array}$ & $\begin{array}{l}\text { Walker, walking stick and } \\
\text { exercise instructions }\end{array}$ \\
\hline $\begin{array}{l}\text { 11) Woman, } 88 \text { years } \\
\text { (presented later as } \\
\text { case 2) }\end{array}$ & $\begin{array}{l}\text { Client was hurt in an acci- } \\
\text { dent and is in poor condi- } \\
\text { tion vs. does not follow } \\
\text { the given mobility exer- } \\
\text { cises when alone }\end{array}$ & & $\begin{array}{l}\text { Walker, exercise instructions } \\
\text { and medicine dispenser }\end{array}$ \\
\hline 12) Man, 56 years & $\begin{array}{l}\text { Client's will to maintain } \\
\text { mobility vs. worker treats } \\
\text { this superficially }\end{array}$ & & - \\
\hline 13) Woman, 76 years & $\begin{array}{l}\text { Client's weak condition } \\
\text { vs. the worker implement- } \\
\text { ing the MA }\end{array}$ & $\begin{array}{l}\text { Start going out with a neigh- } \\
\text { bor }\end{array}$ & $\begin{array}{l}\text { Walking stick, apartment } \\
\text { walls as walking aid }\end{array}$ \\
\hline
\end{tabular}

Table 1: An overview of the analysis of contradictions, motives and artifacts in the studied home care visits 
In four of the analyzed cases, the contradictions emerged between the client's desire to get better and their low motivation and / or pessimism towards their own abilities to move. In these cases, the client was usually well aware of the need to exercise but resisted doing so in their daily life. In nine of the cases, the contradictions emerged between the client and the worker. The client was in these cases usually motivated and very willing to physically exercise. In some cases, the client's motive to increase their mobility related to issues outside of home, such as a desire to go to the summer cottage. Some clients also initiated the use of innovative artifacts supporting the implementation of the MA during the home care visit, but the worker was not always responsive towards these wills. In some of the studied home care visits, the workers seemed to lack an awareness of the contradictions and the MA was thus not implemented. The motive of the visit for the workers was then to concentrate on traditional tasks and tools, such as dispersion of medicine and measuring the client's blood pressure. In some cases, the workers left the responsibility to exercise to the client or to their colleagues in home care.

Despite the contradictions between the client and the worker, in 11 cases a shared motive bet-ween the worker and the client on the meaningful use of the MA developed. In two cases no shared motive appeared. Some of the workers especially actively tried to facilitate the incorporation of mobility exercises to the client's daily life. Yet, all of the workers' efforts for mobility enhancement focused on changes in the client's mobility habits at home, not including the client's mobility needs external to the home environment. The artifacts used by the clients during the home care visits were for example a dumbbell and a kitchen chair supporting the implementation of MA. Artifacts used by the home care worker that restricted the implementation were for example a blood pressure meter and medicine dispenser. In the following, we present the analysis of the two case examples of the implementation of MA.

\section{Case 1: Movement-supporting device fostering the implementation of the Mobility Agreement}

The home care client is a 87- year-old woman. She was physically very active when younger. The client experiences herself as in a good condition. The aim of the visit was to implement a part of MA named capability test and to try some mobility exercises with the client. The nurse viewed the client as capable of conducting domestic duties and mobility exercises. During the visit, the nurse instructed the client to do a series of mobility exercises and the client carefully followed the instructions. In the following episode the client showed the nurse how she uses the movement-supporting device.

Nurse: Could you show me how... (client immediately walked to the electric movement-supporting device to turn it on). C: Yes, of course I can show you. N: What do you call it if not a movementsupporting device? . C: I have not given it any name. It seems to have been agreed that when a nurse visits you every Monday and Thursday, then every time there will be a moment for a mobility exercise with this movement-supporting device. Has this taken place? C: No it has not. I sometimes use it on my own when I remember. N: Yes, our nurses need to improve their practice, they should remind you always (to use the device). C: Yes. N: I will give them a message that they should remind you. It is so good for your feet and in particular your back to keep it in good shape.

The client was supposed to use the movement-supporting device at her home regularly. During this home visit, a contradiction emerged when it turned out that the client had not used the device as agreed. The client was supposed to use it twice a week assisted by a home care employee. Despite her rather good physical condition, the client did not move or do exercises regularly in her daily life and knew that she needed more exercise to 
maintain her ability to walk. The home care nurses had not kept the agreement for helping the client to use the device during home visits.

Starting a mobility exercise with the movement-supporting device during the visit seemed easy for the client. She was very willing to do exercises and carry them out according to the nurse's instructions. Then the nurse changed the subject from the movement-supporting device towards discussing a capability test. This was where the kitchen chair and a dumbbell became important artifacts that the client used, partly together with the help of the nurse. In the following, the capability test was being discussed and the mobility exercises tried by the client.

\begin{abstract}
$\mathrm{N}$ : It seems that this capability test has not been done with you, so would you like to do it now? . C: Yes, it is ok. The nurse went to get a kitchen chair for the client to do the capability test. The client very easily got up from the chair for five times as she was instructed by the nurse. N: Great! Great! Very well done, it did not even take long.

Then the nurse asked the client to pick up a dumbbell from the floor. This was also very easy for the client to do. The chair was also used as a movement support when the client did balance exercises. She then leaned on the back rest of the chair and carried out some hand movements with a dumbbell.

Nurse: Ok, great! We are in a situation where you have a good physical capability. You are physically in a really good condition but our girls (home care employees) have some improvement to make. They must remember this... what is the name of this machine again? Remember to make use of it. Client: Yes!. Should I use it every day? N: It will not hurt, but you should use it at least twice a week. When they come over to visit you and remind you. N: Have you done any mobility exercises on your own? C: Well, not really. The client said that she needed help from home care employees to do the exercises in the right manner and the nurse agreed.
\end{abstract}

The motive for change was shared between the client and the worker (nurse) in this case. The worker was very encouraging and stated that in future the client should do mobility exercises with the movement-supporting device with the help of home care nurses and get up from the chair ten times a day. The client reacted to this in a very positive way. The nurse left the client an exercise program, which she could show to the other home care employees to remind them that she needs to exercise during their visits. The client and the nurse used the movement-supporting device and the exercise program as important artifacts for the further implementation of the MA. The nurse made a promise during this visit to the client to engage her colleagues next visiting the client to take responsibility for using the movement-supporting device with the client.

\title{
Case 2: Medications and dispenser as inhibiting the implementation of the Mobility Agreement
}

Home care client is a 88 -year-old woman. She has multiple illnesses, facial paralysis and an artificial hip. She experiences herself as being in bad physical condition and considers many daily tasks as challenging.

The aim of the visit was to evaluate the client's daily mobility. The client sat at the kitchen table during the whole visit. The home care worker (a nurse) was mainly turned away from the client and concentrated on the food she was preparing for the client. The nurse drew from rules and operating procedures of home care but simultaneously seemed a little worried about the client's mobility and condition. A contradiction appeared during the visit as the nurse dominantly concentrated on the heating of food for the client and on distributing medicine to the client's medication dispenser. The client, on the other hand, expressed a will to walk down the stairs in order to get better to be able to take part in her 
granddaughter's graduation party. In her talk, the nurse expressed her empathy towards the client's situation and saw her will to go outside the apartment and to the party as a goal.

Nurse (N): It was very unfortunate those fallings of yours. Client (C): It weakened my condition. N: Yes. It was a relapse. Hopefully tomorrow will be a better day!. C: Hope so, hope so!! I really hope I could still walk down there. My granddaughter has a graduation party in two weeks, I must go there. N: So, it would be a goal to get there.

Then the talk shifted to the client's medication as the client mentioned that she had had difficulties opening the dispenser and taking out some of her medication. The nurse started to hand different kinds of medication jars to the client and the client placed medicine into the dispenser while the nurse was preparing her meal or briefly sitting down around the kitchen table with the client. The discussion continued around the client's medication, a topic that thereafter dominated the home care visit.

During the visit, the nurse very randomly, every now and then, asked the client questions about her mobility, but no shared motive for change developed. The client was not motivated to improve her mobility, she had not done most of the exercises she had previously been assigned to do. She had tried walking the stairs for three times.

$\mathrm{N}$ : When did you last manage to do the mobility exercises? Did you do some yesterday? N: How about the stairs? How many times you have been there trying to walk down?. C: I feel that I do not have the strength. N: Your legs do not rise up?. C: Yes, they do not rise up.

Suddenly, however, the client expressed the wish to the nurse to do mobility exercises.

C: You will need to make me do mobility exercises at one point. N: Ok. C: I will not give up (the mobility) for small reasons. As soon as I get rid of this other problem (recover from the operation). $\mathrm{N}$ : Yes. As we have said, even a small movement is good for you. C: Yes, I have remembered to move, I go back and forth like a rabbit. N: You mean with your rollator?. C: Yes, with the rollator, I do not have the courage to go without it. N: Yes.

The client emphasized during the visit that she is interested in doing mobility exercises, but feels that she is not able to perform the movements independently. The nurse asks the client mobility related questions but was mainly occupied with other duties, such as cooking and dispensing medicine with the client. The nurse disregarded the client's initiatives and did not make any attempts to execute mobility exercises with the client in practice. The goal expressed by the client, namely taking part in her granddaughter's graduation party, is left in the air without any concrete attempts to enhance the client's mobility in the near future. Artifacts, such as medications and the dispenser were in the core of the workers' motive of the visit, together with the client's meal and inhibited the implementation of the MA and the enhancement of the client's mobility.

\section{Discussion and Conclusions}

Our study aims at answering the research question of how an innovative concept can be implemented to change and develop home-care practice. We analyzed the implementation of an innovative tool named Mobility Agreement in 13 client visits in Finnish home care. Our data collection was carried out two years after the first implementation effort of the MA and provides insights into the use of the abstract concept of "enhanced mobility" in concrete daily practices of the home care workers and their clients. 
The findings show that the implementation of an innovation cannot be seen as a mere communication and adoption process as emphasized in some diffusion theories ${ }^{12}$. Nor does the understanding of adaptation ${ }^{15}$ or the statement that communication, adoption and adaptation are intertwined, offered by some previous studies ${ }^{13,16}$ sufficiently describe the dynamics of innovation implementation processes in routine-like work activities, such as home care. An expanded view to innovation implementation is needed where implementation is seen as a contradiction-laden transformation process of abstract concepts into concrete contexts ${ }^{9,11}$. Treated as a longitudinal expansive learning process, innovation implementation involves multiple learning actions and challenging rounds of contradiction solving ${ }^{16}$.

Achieving system-level change and development requires a reflection of the implementation process and the emergence of a shared motive between the actors ${ }^{10,17,18,20}$. In our case examples, the identification of the source of the contradiction through reflection was a crucial enabler of the use of the MA promoting the actors' motive to conduct mobility exercises. When a reflection of the current situation and problems did not take place, the motive for mobility enhancement did usually not become shared and inhibited a sufficient application of the MA tool and enhancement of the client's mobility. In case one, the nurse identifies the source of the contradiction through reflection: The other care workers do not sufficiently apply the tool. This is due to a shared motive between care worker and client. In case two reflection about the situation does not take place, the care worker follows her individual motive, which hinders a sufficient application of the tool.

Our study further shows that artifacts, customary to the clients (such as their own kitchen chair) play a crucial role in supporting the implementation process of abstract home care innovations (like the MA). They may enhance sense making and mediate the activity between the actors and between the new concept and the users and they are likely to help solve contradictions. In the studied innovation implementation process, there were, however, also artifacts inhibiting the innovation implementation process that were used by the workers and sometimes also by the clients. These are artefacts that cannot mediate between the actors and the innovation.

Altogether, the implementation process needs to be considered comprehensively, taking into account the whole home care system ${ }^{7,15}$. Referring to the model of expansive learning, implementation is not a linear process initiated by the management or the care worker who is formally the promotor of the innovation. The implementation of an abstract concept into concrete practice is not only a combination of communication, adoption and adaptation, but it is rather a transformation process, which not only adjusts the existing practice to the innovation, but also significantly changes social interaction, understandings and processes. This brings about new contradictions and demands, which require collective resolving to create further innovative solutions and transformation. Hence, implementation should be seen as a continuous expansive learning process ${ }^{22}$. A central role in this process is played by the worker - client interaction. The client becomes a co-innovator when it comes to the implementation of the innovation. Their role needs to be seen beyond being a mere legitimizer of an innovation ${ }^{16}$.

The contradictions depicted in our study can potentially be solved through improved communication between the home care worker, and by the adoption and adaptation of the new activity concept or model ${ }^{15}$. Our core message to organizational management is that, as a crucial factor for promoting successful implementation of an innovative practice, there 
needs to be a continuum and systematic bridging efforts between the abstract design and concrete implementation phases of innovation implementation (see our sub-cycles in figure 1). In our case example the home care workers formally act as promotors of the MA. It shows, however, that they lack awareness of the meaning of the MA. It can be subsumed that a shared motive between innovation designers and promotors is missing. Consequently, platforms are needed that provide time and space for communication improvement, and for connecting contradiction resolution, innovation design, implementation and learning among all actors. The methods and mechanism described in this study can also be found and applied in other contexts beyond health and social care, where innovative concepts are implemented in social practice, such as organizational development, education and learning processes or product and service development.

Our research has limitations as we present only two cases which provide a selective picture of the data. Moreover, our research design lacks a longitudinal approach. These limitations need to be addressed in future studies. To enhance health care and home care innovation implementation, longitudinal case studies are needed in order to further examine how an innovative abstract concept can be implemented to change and develop organizational practice.

\section{References}

1 Williams I. Organizational readiness for innovation in health care: some lessons from the recent literature. Health Services Management Research 2011, 24(4): 213-218.

2 Martin G, Sutton E, Willars J and M Dixon-Woods. Frameworks for change in healthcare organisations: A formative evaluation of the NHS Change Model. Health Services Management Research 2013; 26(2-3): 65-75.

3 Schulz K-P, Geithner S, Wölfel C and J Krzywinski. Toolkit-based Modelling and Serious Play as Means to Foster Creativity in Innovation Processes. Creativity and Innovation Management 2015; 24(2): 323-340.

4 Engeström Y. Activity theory and expansive design. In: Bagnara S and Crampton-Smith G (eds.) Theories and practice of interaction design. Hillsdale: Lawrence Erlbaum 2006; pp. 3-23.

5 Martin G, Weaver S, Currie G, Finn R and R Mc Donald. Innovation sustainability in challenging health-care contexts: embedding clinically led change in routine practice. Health Services Management Research 2012; 25: 190-199.

6 Kajamaa A. Boundary Breaking in a Hospital: Expansive Learning Between the Worlds of Evaluation and Frontline Work. The Learning Organization 2011; 18(5): 361-377.

7 Ansari S, Fiss P and E Zajac. Made to fit: How practices vary as they diffuse. Academy of Management Journal 2010; 31: 67-92.

8 Rye $\mathrm{C}$ and $\mathrm{J}$ Kimberly. The adoption of innovations by provider organisations in health care. Medical Care Research Review 2007; 64: 235-278.

9 Kajamaa A. Unraveling the helix of change: An activity-theoretical study of health care change efforts and their consequences. Helsinki: Unigrafia, 2011.

10 Engeström Y, Kajamaa A. and J Nummijoki. Double stimulation in everyday work: Critical encounters between home care workers and their elderly clients. Learning, Culture and Social Interaction, 2014 published online before print; DOI: 10.1016/j.lcsi.2014.07.005.

11 Kerosuo H, Kajamaa A and Y Engeström. Promoting innovation and learning through Change Laboratory: An example from Finnish health care. Central European Journal of Public Policy 2010; 4(1): 110-131.

12 Rogers E. Diffusion of innovation. 5th ed. Free Press, New York, 2003. 
13 Rogers E, Singhal A and M Qinlan. Diffusion of innovation. In: Stacks D and Salwon M. (eds) An integrated approach to communication theory and research. 2nd ed. New York: Routledge, 2009, pp. 418-434.

14 Mol M and J Birkinshaw. The role of external involvement in the creation of management innovations. Organization Studies 2014, 35(9): 1287-1312.

15 Ansari S, Reinecke J and A Spaan. How are practices made to vary? Managing practice adaptation in a multinational corporation. Organization Studies 2014, 35(9): 1313-1341.

16 Volberda H, Van Den Bosch F and O Mihalache. Advancing management innovation: Synthesizing processes, levels of analysis and change agents. Organization Studies 2014, 35(9): 1245-1264.

17 Sannino A, Daniels H and K Gutierrez, K. Learning and expanding with activity theory. Cambridge; New York: Cambridge University Press, 2009.

18 Schulz K-P, Kajamaa A and H Kerosuo. Creating innovative work practices through reflexive interventions. International Journal of Work Innovation 2015, 1(2): 143-160

19 Schulz K-P, Geithner S and T Kawamura. Applying toolkit-based modeling and serious play - A Japanese case study on developing a future vision of a regional health care system, In: Gurtner S and Soyez K (eds.) Challenges and opportunities in health care management. Heidelberg, Berlin: Springer, 2015, pp. 291-305.

20 Engeström Y and F Blackler. On the life of the object. Organization 2005, 12(3): 307-330.

21 Virkkunen J and H Ahonen. Supporting expansive learning through theoretical-genetic reflection in the Change Laboratory. Journal of Organizational Change Management 2011, 24(2): 229-243.

22 Engeström Y and A Sannino. Studies of expansive learning: Foundations, findings and future challenges, Educational Research Review 2010, 5(1): 1-24.

23 Engeström Y, Kerosuo H and A Kajamaa. Beyond Discontinuity: Expansive Organizational Learning Remembered. Management Learning 2007, 38 (3): 319-336.

24 Marcus G. Ethnography in/of the world system: The emergence of multi-sited ethnography, Annual Review of Anthropology 1995, 24(1): 95-117.

25 Saldana J. The coding manual for qualitative researchers. Sage, Thousand Oaks 2009. 